\title{
Case Study of Local Revitalization in Indigenous Areas of Taiwan: Using the Namasia District as an Example
}

\author{
Hsiao-Ming Chang1, Chun-You Lin², Xiepin Zheng ${ }^{3 *}$ \\ ${ }^{1}$ School of Physical Education, Putian University, Putian, China \\ ${ }^{2}$ Guangdong-Taiwan College of Industrial Science \& Technology, Dongguan University of Technology, Dongguan, China \\ ${ }^{3}$ School of Basic Education, Putian University, Putian, China \\ Email: 1815649662@qq.com, juniorchou@qq.com, ${ }^{\star} 765894078 @ q q . c o m$
}

How to cite this paper: Chang, H.-M., Lin, C.-Y. and Zheng, X.P. (2022) Case Study of Local Revitalization in Indigenous Areas of Taiwan: Using the Namasia District as an Example. Open Journal of Applied Sciences, 12, 10-18.

https://doi.org/10.4236/ojapps.2022.121002

Received: December 14, 2021

Accepted: January 7, 2022

Published: January 10, 2022

Copyright $(2022$ by author(s) and Scientific Research Publishing Inc. This work is licensed under the Creative Commons Attribution International License (CC BY 4.0).

http://creativecommons.org/licenses/by/4.0/

\begin{abstract}
This study aims to analyze the operational model of the local revitalization plan implemented in the indigenous tribes in Taiwan. It treated Namasia District of Kaohsiung City, Taiwan as the subject, and conducted an investigation by qualitative research. According to the findings, the practices of local revitalization are based on the following conditions: 1) local government leads the plan of revitalization; 2) it finds DNA to develop local revitalization; 3) it seeks investment from enterprises; 4) it accepts the assistance from academic and professional teams for the integration and development of innovative and creative products; 5) it reinforces the ethnic consciousness, supports local residents and industries, and participates in the execution of plans.
\end{abstract}

\section{Keywords}

Local Revitalization, Regional Planning, Indigenous Peoples, Ecotourism

\section{Introduction}

Taiwan tends to value northern Taiwan while neglecting southern Taiwan, and this trend of global urban concentration results in a severe unbalance of regional development. Furthermore, there is the crisis of population aging and fewer children. Thus, Taiwan relies on the experts' packaging designs to promote agricultural specialties, and local industries can be highlighted with local features. We expect the collaboration between central and local governments to solve problems, such as local population aging, cultural preservation, and industrial development, through the "local revitalization by design" project, which focuses 
on social enterprises and local revitalization [1]. According to the project, in Taiwan, 48 towns are located in indigenous areas and account for nearly $90 \%$ of the current indigenous areas (55 places). These towns are mostly located in the Central Mountain Range and eastern Taiwan, which have limitations on land development and industrial development, lack job opportunities for young people and have inferior public service levels [2]. According to the report of Council of Indigenous Peoples, emigration would result in a change of the local population structure. Emigration in indigenous areas mostly refers to young adults with a higher level of education, which leads to population aging in the said areas and results in loss of manpower capital. Moreover, these areas lack young adults to practice tribal development and cultural inheritance, thus, government strategies should rely on the assistance of local employment and entrepreneurship, the support of professional talents to develop local industries, and reinforcement of public services and facilities, such as education, medical care, and external transportation [2]. Like other towns, the Namasia District has encountered a rapid population decline, as most young adults leave the local area to work in cities, which leads to the constant loss of the young population in the tribe. In order to encourage young people to return to their hometown to work, the district launched a project of local revitalization, which became the model selected by the National Development Council. Thus, this study aims to analyze the operational model of the plan in the district and expects that the analytical result will serve as the reference for indigenous areas and tribes that intend to develop and revitalize their local industries.

\section{Plan of Local Revitalization}

\subsection{The Origin of the Plan}

Taiwan has encountered the same issues as Japan, and after following Japan's plan and developing a successful case, in 2017, the government of Taiwan planned a direction for local revitalization. "Local revitalization" relies on local spontaneous thinking; in other words, the design must be originated according to local "place, production, and people", and it must construct a local team that focuses on sustainable operations and development. Through the project of "local revitalization by design" and successive processes, it aims to integrate excellent local and foreign manpower to strengthen local industry development and local culture, and present landscape aesthetics that highlight the area. The main strategy of the "local revitalization by design" project is to first explore the advantages of the original local resources of "place, production, and human", and validate their uniqueness and core values. The elements of place, production, and human are essential in implementation. The design and guidance of "originality + innovation + entrepreneurship" creates a relation effect of local "work, products, and goods" with "the force of design, production, and marketing" to accomplish the goal of "local revitalization" [1]. The objective of the "National Strategic Plan of Local Revitalization" is to maintain a total population of at least 20 million in the 
future, expect equality between the local population through immigration and emigration by 2022 , the return of local populations by 2030 , successive immigration to the island, and avoid population concentration around the capital, in order to create a "balanced Taiwan". The implementation of this project was based on humans and local development, and it explored and used local DNA and the characteristics of resources. Through the interdisciplinary integration of "business investments in hometowns", "the introduction of technology", "the integration of departmental revitalization resources", "social participation", and "brand construction", the project proposed and implemented local revitalization [2]. The promotion of local revitalization relies on central and local governments, as well as long-term cooperation between the government and the private sector, thus, the outcome cannot be shown in short term. At the early stage, phase one would be based on four years, and 2019-2022 would be Phase 1. At the end of each year, the project will examine the situations of the implementation of local revitalization, the resources, and the related measures by rolling review [2].

\subsection{Related Research}

Relevant studies have pointed out that in Taiwan, for example, Chang (2020) studied Yunlin Gukeng area. The key factors affecting local revitalization development are "local creative talent cultivation", "sustainable consumption and production mode", "youth returning population", "private enterprise investment in hometown" and "consensus forming vision" and other index factors [3]. Liou (2020) took Wumile community in Tainan as the research object. The results showed that: firstly, although the development of local DNA elements, including blue dye, rush weaving and dowry culture, is small, it is also a part of local culture. Through experience marketing, it increases highlights and has a small positive economic development for the community. Secondly, combine the products with biotechnology to develop health food or maintenance products, and increase employment opportunities and business opportunities through the investment of schools and the entry of enterprises. Finally, the key factor for success lies in the transformation of agricultural products, that is, the transformation of rice. Rice has formed the way of experience marketing and biotechnology [4]. Tsai (2021) takes Dongshi township as the research object to analyze how to develop local creation. The results show that Dongshi township has rich natural ecology, simple cultural customs and is famous for its agricultural and fishery specialties. The villagers have expectations for the local prosperity, but they can't keep pace with the times due to the lack of creation concept and related resources. Therefore, we should take "revitalizing local education", "elite giving back to their hometown", "building a characteristic home", "government and private participation" and "building industrial brand" as countermeasures [5]. Tung (2021) studied the value creation and brand marketing of water chestnut commodities in Guantian District, Tainan City under circular economy. In summary, it was found that the "Guantian water chestnut" brand commodities are in 
line with the United Nations Sustainable Development Goals. Based on this, the following suggestions are put forward: 1) in terms of industry, diversified marketing can be promoted through inventory of local resources; 2) in terms of government, connecting various resources can expand local creative energy; 3) in terms of schools, local brand marketing can be connected through the addition of USR plan of the Ministry of Education; 4) In terms of community, the mutually beneficial cooperation model of Guantian Wujin community cooperative can promote sustainable development [6]. Therefore, from the above cases, finding out the DNA elements created by local governments and the integration and development of local and enterprises are important factors for development.

\section{Research Method}

\subsection{Research Scope}

The Namasia District is located in a mountainous zone in the northeastern part of Kaohsiung City, Taiwan, its square measure is $252.9895 \mathrm{sq} \cdot \mathrm{km}$, and it is one of three indigenous areas in Kaohsiung City. In the area, there are different peoples, $70 \%$ of which are Bunun, but there are also Kanakanavu, Hla'alua, Atayal, Paiwan, and Han Chinese. The area is surrounded by mountains in the northeast direction, the terrain is high, and the western mountain ridge is wider while the northern slope is lower. The area has mostly mountain slopes, a few ladder fault areas, a riverbed platform, a mid-slope plateau, and a plateau ladder in the basin, thus, it is overall surrounded by high mountains with valleys and ladder faults. The south is round, the central part is wider, and the north is long and narrow, thus, it resembles a calabash basin [7].

\subsection{Data Collection}

This study adopted qualitative research, which explored the development of local revitalization in Japan and collected the policies and plans of local revitalization in Taiwan. In addition, through the internet and information related to the Namasia District, this research probed into the "environmental resources" of the area, including its unique tribal history, and natural, social, and industrial resources: meaning the DNA of local development. Furthermore, after analyzing the environmental resources of the tribe, this research conducted an on-site investigation of the resources, which were generalized to determine authenticity. Finally, this research interviewed the indigenous peoples and residents of the local tribe.

\section{Results}

\subsection{Revitalization DNA and the Characteristics of Resources}

The implementation of the project for local revitalization is based on humans and local development, which generalizes and applies local DNA and resource features. This study concludes the revitalization DNA of the Namasia District, as 
shown in Table 1.

\subsection{Plan of Revitalization}

According to the district executive of Namasia District, the tourists of Namasia can watch the dance of butterflies and the ecology of fireflies at night. Based on local industries, the project constructs in-depth ecotourism and aims to cooperate with colleges, universities, and enterprises, and combine professional techniques to strengthen the development of the feature industries of Namasia according to the strategy of local revitalization. Thus, in order to revitalize the area, preserve the local indigenous culture and natural landscape, and encourage young people to return to the tribe to work and settle down, the Namasia District Office and the Leshui Company cooperated with the Kaohsiung Medical University and the National Kaohsiung University of Science and Technology and planned the tourism project of "Homecoming Path: which is a project that focuses on in-depth culture and local ecotourism revitalization", as based on multiple tribal and indigenous cultures with local characteristics and rich ecotourism resources. This project integrates local food services, hostels, local agricultural production and supply, natural ecology experiences, tribal culture, and art experiences, where the purpose is to create an in-depth tourism experience based upon "indigenous culture" and "natural ecology". Thus, visitors to Namasia can experience indigenous peoples' "food culture from production to the table", "cultural ceremonies", and the "ecology of fireflies", which are popular in recent years.

According to the $\mathrm{CEO}$ of the Leshui Company, the "revitalization project of the Homecoming Path" is based on a work division to integrate tourism trips. Thus, through a one-station window, tourists can explore Namasia, including tourism, ecology, culture, and agricultural specialties, in order to enhance the

Table 1. Revitalization DNA and resource characteristics of namasia district.

\begin{tabular}{ll}
\hline \multicolumn{1}{c}{$\begin{array}{c}\text { Natural ecology and } \\
\text { environmental resources }\end{array}$} & Cultural heritage of indigenous peoples \\
\hline $\begin{array}{l}\text { 1) Ecology of fireflies see (Figure 1) } \\
\text { 2) Century Valley }\end{array}$ & 1) Indigenous culture with multiple \\
3) Nasilan Bridge & characteristics \\
4) Maya Bridge & 2) Takiaru (Hla'alua) (see Figure 2) \\
5) Laoren River & 3) Mikong and Kaisisi Cakuran \\
6) Kamanu & (Kanakanavu) (see Figure 3) \\
7) Masinghalan Scenic Bridge & 4) Ma-naq-tainga (Bunun) (see Figure 4) \\
8) Wuchuan River Waterfall & 5) Tangaanua Shrine relic \\
9) Tuoyachiyi Waterfall & 6) Indigenous peoples' museum of Namasia \\
10) Yuda Mountain & 7) Agricultural specialties \\
11) Sion Mountain & 8) Natural foods of indigenous peoples \\
12) Sanminhuo (ghost fire) & 9) Tribal market \\
13) Nanzihsiian River Ecological & \\
Zone and Wetland &
\end{tabular}




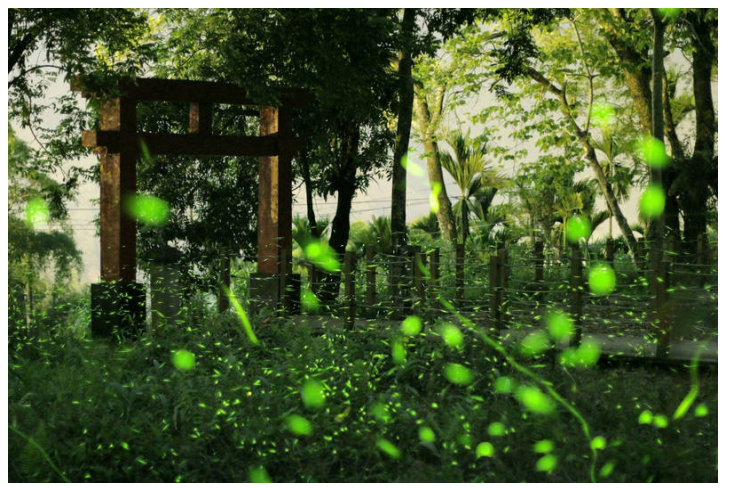

Figure 1. Ecology of fireflies [8].

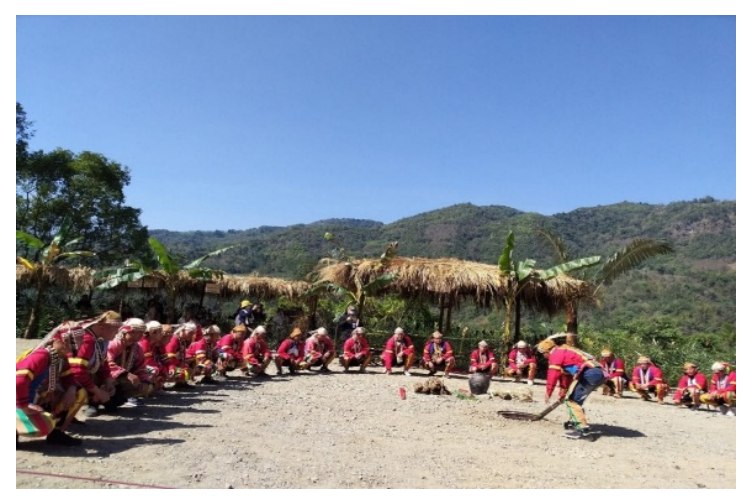

Figure 2. Takiaru of Hla'alua [9].

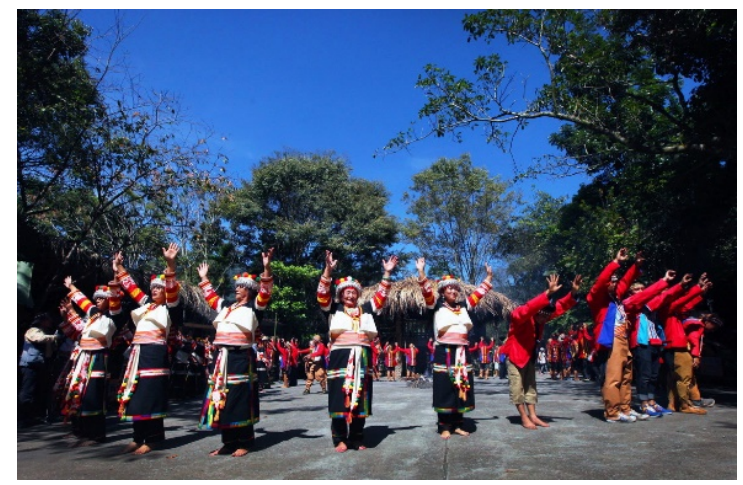

Figure 3. Mikong of Kanakanavu [10].

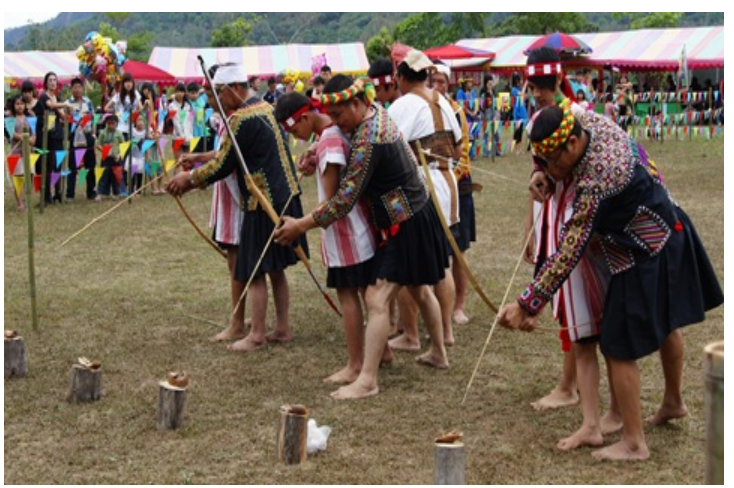

Figure 4. Ma-naq-tainga of Bunun [11]. 
development of local feature industries [12]. At present, $86.99 \%$ of indigenous peoples in Namasia District live in more than 7 indigenous tribes, and they are mostly Bunun. Local indigenous cultural ceremonies are diverse and the wellknown activities include Ma-naq-tainga of Bunun, Mikong and Kaisisi Cakuran of Kanakanavu, and Takiaru of Hla'alua. In order to reinforce and maintain traditional tribal culture assets, and encourage tribal youth to work in their hometown and engage in local industries, the "revitalization project of Homecoming Path" relies on the original Namasia District Office, Minsheng Elementary School, and the designated site for cultural ceremonies, to construct a place for the cultural ceremonies of Kanakanavu and Hla'alua peoples, which are the majority in the area, as well as Bunun peoples, thus, there is a sense of urgency to preserve local culture and attract tourists to experience the various lifestyles and sand cultures of indigenous peoples. In addition to cultural ceremonies, the "revitalization project of the Homecoming Path" has established tribal markets to integrate the original agricultural products, handicrafts, and featured foods to strengthen the tourism experience; for example, the "Dream Workshop", which takes place at the cultural ceremony site, designs various cultural and creative products with natural plants, such as bamboo, Sapindales, coix lacryma-jobi, and Bentham. During this workshop, tourists can taste the coffee and the wild aiyu jelly produced by the local tribe, and experience bead stringing DIY with bamboo. The founder of the workshop is a Bunun handicraft teacher, who combines bamboo with traditional Bunun culture to enhance the tourism experience in DIY.

In recent years, Namasia has successfully restored its firefly population. There are 20 kinds of fireflies in the area, which accounts for $1 / 3$ of the species around Taiwan, and they are mostly Luciola cerata. During the firefly festival in March and April every year, the sparkling light show of these amazing creatures at night attracts tourists from the metropolitan areas to visit Namasia. However, as the firefly festival is only two months long, it cannot result in a local tourism industry that is able to upgrade local development and industrial output value. Therefore, in order to increase the output value of in-depth tourism, the "revitalization project of Homecoming Path" planned 8 trails that feature firefly-watching, in order to create the ecology of fireflies, including Longfeng Trail, Rabinia Trail, Chingshan Section Trail, Beishengming Collector Street Trail, Tangaanua Trail, Changshulin Trail, Old Minchuan Elementary School Trail, and Nanshalu Trail. The plan of these trails aimed to connect the indigenous cultures and ecological characteristics of different areas of Namasia, in order to enhance the tourism travel experience. Furthermore, the project developed a new tourism site in $\mathrm{Na}$ masia, Wengweng Valley, which includes natural gorge landscapes, such as vertical cliffs, giant rocks, deep pools and waterfalls, and indigenous culture relics to create unique tourism experiences. This site even connects with the future Major Kaohsiung Tourism System, which allows tourists to thoroughly experience the unique landscape and ecological diversity in Namasia. 


\section{Conclusion and Suggestions}

\subsection{Conclusion}

According to research findings, this study finds that the project of local revitalization in Namasia District aims to preserve local indigenous culture and natural landscapes to attract tribal youth to return to and work in their hometown. The steps of execution are shown, as follows: 1) local government leads the project of revitalization, constructs a local revitalization team, and explores DNA to develop local revitalization; 2) the Leishui Company (business investment) cooperates with the Kaohsiung Medical University and the National Kaohsiung University of Science and Technology; 3) the project integrates local food services, hostels, local agricultural products and supply, natural ecological experiences, and tribal culture and art experiences, and develops the tourist product of the "Revitalization Project of Homecoming Path"; 4) it reinforces ethnic consciousness, promotes the vision to practice local revitalization, and strengthens the support and execution of local residents and industries to participate in the project; 5) and at the end of every year, it evaluates the outcomes according to the rules, in order to review and improve the project.

\subsection{Suggestions}

While the local revitalization project in Namasia District is in the development phase, the area possesses a solid foundation of revitalization DNA, particularly the ecology of fireflies, which is a unique natural landscape. According to the concept of five arrows for the development of local revitalization, in the future, Namasia District should reinforce its "business investment in the hometown". Based on the concept of sustainable development, the local resources can be packaged as different ecotourism products to attract tourists to visit. In addition, it is extremely important to "construct a brand"; with its rich firefly ecology, Namasia District attracts numerous visitors to appreciate the local ecology every year, climb the mountains, camp, and experience outdoor recreational activities. Thus, in the future, it is critical to construct a brand through the ecology of "fireflies" with local tourism industries (hostels, leisure farms, and camping sites). Since agricultural products in Namasia District are abundant, and some are based on organic cultivation, in the future, the promotors of the project for local revitalization in the area can integrate local agricultural specialties to enhance local job opportunities to encourage the young people to return to and work in their hometown.

\section{Acknowledgements}

This study was supported by a grant from National Social Science Foundation of China (No.18BMZ130).

\section{Conflicts of Interest}

The authors declare no conflicts of interest regarding the publication of this paper. 


\section{References}

[1] National Development Council (2017) Guidance of Planning of the Project "Local Revitalization by Design”. National Development Council, Taipei City.

[2] National Development Council (2018) National Strategic Plan of Local Revitalization (Ratified Version). National Development Council, Taipei City.

[3] Chang, J.-C. (2020) Identifying Key Factors Affecting Regional Revitalization Development: A Case Study of Gukeng Township, Yunlin County. Chung Hua University, Hsinchu.

[4] Liou, K.Y. (2020) Discussions on the Key Factors of the Success of "Regional Revitalization"-A Case of Jingliao Community in Tainan City. National Penghu University of Science and Technology. Master's Thesis, National Penghu University of Science and Technology, Penghu.

[5] Tsai, S.-D. (2021) A Study of Regional Revitalization Overturning the Economic Life of Dongshi Township. Marketing. Master's Thesis, National Chung Cheng University, Chiayi.

[6] Tung, Y.C. (2021) Study on Circular Economy of the Guantian Black-Golden Commodity Value Creation and the Construction of Brand. Marketing. Master's Thesis, Kun Shan University, Tainan.

[7] Namasia District Office (2021) Introduction of Namasia-Location. https://namasia.kcg.gov.tw/cp.aspx?n=19D125D877556410

[8] Liberty Times (2021) Arrival of Firefly Festival, Firefly-Watching Bus in Namasia. https://news.ltn.com.tw/news/life/breakingnews/3456262

[9] Newsmedia (2021) Takiaru Held in Namasia after Five Years-Inheritance of Hla'alua Culture. https://newsmedia.today/

[10] Mikong of Kanakanavu (2021) https://cyberisland.teldap.tw/g/qwhcsUntgdAdefbBImFSles

[11] Liu, W.T. (2011) Series of Song of Spring (3) Ma-naq-tainga of Namasia One Year after Homecoming. https://www.88news.org/posts/11419

[12] National Development Council (2021) Case of Revitalization: Indigenous Culture and Ecology, Local Revitalization of Namasia by "Homecoming Path". https://www.twrr.ndc.gov.tw/case/case-detail?uid=5b91e34e-aafe-4aec-bdbc-fbbdec $\underline{727 \mathrm{bf} 4}$ 